\title{
Perceptions of People with Special Needs Regarding Autonomous Vehicles and Implication on the Design of Mobility as a Service to Foster Social Inclusion
}

\section{OPEN ACCESS}

Edited by:

Peter David Tolmie,

University of Siegen, Germany

Reviewed by:

Efthimios Bothos,

Institute of Communication and

Computer Systems, Greece

Cecily Morrison,

Microsoft Research (United Kingdom), United Kingdom

*Correspondence:

Benjamin Nanchen

benjamin.nanchen@hevs.ch

Specialty section:

This article was submitted to

Digital Impacts,

a section of the journal

Frontiers in Human Dynamics

Received: 31 July 2021

Accepted: 30 December 2021

Published: 26 January 2022

Citation:

Nanchen $B$, Ramseyer $R$, Grèzes $S$,

Wyer $M$, Gervaix A, Juon D and

Fragnière $E$ (2022) Perceptions of

People with Special Needs Regarding Autonomous Vehicles and Implication on the Design of Mobility as a Service

to Foster Social Inclusion.

Front. Hum. Dyn 3:751258.

doi: 10.3389/fhumd.2021.751258

\section{Benjamin Nanchen *, Randolf Ramseyer, Sandra Grèzes, Mélanie Wyer, Alain Gervaix, Dominic Juon and Emmanuel Fragnière}

Institute of Tourism, HES-SO, Sierre, Switzerland

Worldwide, more than one billion people live with disabilities. People with disabilities (PWD) have needs in terms of autonomy, social participation and inclusion. Mobility is one condition for them to be included in society and participate in social life. Autonomous vehicles (AVs) can be part of the concept of Mobility as a Service (MaaS) that enables us to rethink the policy of mobility. However, the way these new autonomous mobility services are designed could exclude PWD. To prevent that, universal design principles and inclusive design could help policymakers and public transport companies design new means of transport that are accessible to all. However, perceptions of PWD regarding MaaS in general and AVs are not well documented. This article presents qualitative research about these perceptions. Eight semi-directive interviews were thus carried out on the subject. Based on these findings, we developed an integrative model to accompany and orchestrate such AV design developments. This integrative model will help policymakers and public transport companies rethink mobility concepts while incorporating $\mathrm{AVs}$ and make them accessible to ensure the social inclusion of PWD.

Keywords: disability, special needs, inclusion, mobility as a service (MaaS), autonomous vehicles (AVs)

\section{INTRODUCTION}

According to the World Health Organization, more than one billion people live with disabilities worldwide ${ }^{1}$. With the ageing population, disability will become an even greater concern, particularly in Western countries (Uhlenberg, 2009). To catch up with this societal challenge, the United Nations proposed the Convention on the Rights of Persons with Disabilities (CRPD), ratified by 181 countries ${ }^{2}$. The CRDP marks a paradigm shift from the medical model of disability to the social model of disability, whose basic premise is that the socially constructed environment excludes people with disabilities (PWD) from social participation. In the context of mobility, the main reason for people with disabilities not using a mobility service when they need it is not their impairment but the lack of accessibility. The mobility of people is one of the major elements promoting their inclusion in

${ }^{1}$ https://www.who.int/news-room/fact-sheets/detail/disability-and-health.

${ }^{2} \mathrm{https} / / /$ www.un.org/development/desa/disabilities/convention-on-the-rights-of-persons-with-disabilities.html. 
society. As a result, PWD risk being excluded from social cohesion, which is the necessary cement of our democracies. Moreover, recent international laws require that all measures be taken to ensure that all PWD are offered solutions to obtain equal treatment in this area. Switzerland, with its monistic conception of the law, has ratified these treaties and international agreements but is slow to implement them in practice.

In Switzerland, where this research is conducted, approximately 1.6 million people are affected by disability ${ }^{3}$. Switzerland ratified the CRPD in April 2014 and must eliminate barriers faced by PWD, protect them against discrimination and promote their inclusion and equality in civil society. The Federal Constitution prohibits any form of discrimination. The Federal Act on the Elimination of Inequalities Affecting Persons with Disabilities ${ }^{4}$ (LHand) states that inequalities may be encountered in access to a construction, installation, housing, equipment, or vehicle for design reasons. For public transport services, the Swiss law mentions that inequality exists if the "access for persons with disabilities is not possible for structural reasons or is only possible with difficulty". 5 Furthermore, the Swiss government has set up principles related to public transport stations, stops, communication systems, ticketing systems and vehicles. However, according to the Swiss Federal Statistical Office $(2020)^{6}$, getting around, whether for short or long distances, is often not easy for PWD. Their difficulties are not only linked to their physical or mental disability but also to the built or technological environment (e.g., buses inaccessible to wheelchair users, lack of sound information or guides on the ground).

As part of this applied research, we conducted in-depth study, based on semi-structured interviews and immersions, of the daily mobility of PWD. We zoomed in on their perception of autonomous vehicles (AVs), on-demand service and first-mile, last-mile (FMLM) service. Based on our findings, we propose an integrative model to orchestrate the design of AV experience for PWD. To illustrate the application of this integrative model, we use the case of the city of Sion in Switzerland, where AVs have been tested since 2016. In 2021, a new route was planned in Uvrier, a residential quarter of Sion. On this new route, ondemand service and FMLM service have been tested. Furthermore, a focus will be given to the needs of PWD. This case is perfectly suited for the application of our integrative model.

This paper is organised as follows. In Section 2, we present a review of the scientific literature that leads us to position our research on PWD in a future context of transport experience design through AVs. In Section 3, we present the qualitative survey methodology used in this research. In Section 4, we

${ }^{3}$ https://www.bfs.admin.ch/bfs/en/home/statistics/economic-social-situationpopulation/equality-people-disabilities/disabilities.html.

${ }^{4}$ https://www.admin.ch/opc/fr/classified-compilation/20002658/index.html. ${ }^{5} \mathrm{https} / / /$ www.fedlex.admin.ch/eli/cc/2003/667/en, Article 2 Definition, Alinea 3. ${ }^{6} \mathrm{https} / / / \mathrm{www} . b f s . a d m i n . c h / b f s / f r / h o m e /$ statistiques/situation-economiquesociale-population/egalite-personnes-handicapees/participation-societe/mobilite. html. summarize the main findings of the qualitative survey and discuss them in detail. Based on the findings, Section 5 proposes an integrative model to orchestrate the design of AVs experience for PWD. This section presents an illustration of immersion episodes conducted in real life and our design ideas presented in a service blueprint that provide an overview of the experiences of PWD who might use an AV for mobility purposes. Since the implementation phase could not take place due to COVID, we also propose in Section 5 an adapted service design methodology to pursue the staging and production of AVs for PWD and policy recommendations for universal and inclusive AVs experiences. Finally, the conclusion indicates the limitations of our approach as well as directions for future research.

\section{LITERATURE REVIEW}

Here, our goal is to promote upstream inclusive design to better consider the needs of people with disabilities. To position the purpose of the research, we report some themes of the literature review structured in the following way.

This literature is based on the postulation that notions of the medical model of disability are not sufficient, and the social model of disability must be considered to relevantly design AVs for PWD. Some findings are reported in this regard, particularly in relation to the link between the notions of disability and accessibility in a social context, which will be explained in the sub-section "Disability and accessibility".

Then, in the section "Mobility as a Service (MaaS) for People With Disability (PWD)", once the notions of disability and accessibility have been defined, the notion of Mobility as a Service is introduced by focusing MaaS on aspects of digitalisation and thus smart mobility that can offer PWD automated advantages to facilitate their mobility.

The Section "AVs for PWD" then focuses on the specific MaaS of AVs and allows us to concentrate on the scientific papers that precisely touch the scope of our research.

Finally, the section "Designing for all through universal design and inclusive design" gives the theoretical elements to approach the experience design of AVs for PWD on the principles of universal design and thus to include not only PWDs but all people with reduced mobility (e.g., the elderly and small children).

\section{Disability and Accessibility}

The medical model of disability considers disability a personal problem requiring medical intervention to normalise the disabled body. In contrast, the basic premise of the social model of disability is that the socially constructed environment excludes PWD from social participation. In a social constructionist approach to understanding the accessibility phenomenon, disability is seen as a social construct that varies across culture and time (Darcy and Buhalis, 2010).

For PWD, mobility is linked to accessibility. Different geographical levels-micro, meso and macro-are related to accessibility. At each level, physical access, access to information, social activities and services can be distinguished. Three dimensions-physical access, sensory access and access to 
communications-compose accessibility (Eichhorn and Buhalis, 2010).

Leisure constraint theory focuses on barriers, nonparticipation in entertainment activities and lack of leisure opportunities (Darcy and Buhalis, 2010). Three categories of constraints exist: intrapersonal (related to the person, his/her psychological, physical, or cognitive state), interpersonal (related to social interactions or relationships in social contexts) and structural, the latter including, for example, financial issues, lack of time, and laws (Daniels et al., 2005). These barriers and constraints are well documented. To design an accessible service, it is important to understand how barriers are socially constructed and how to transform them.

PWD still have significant barriers to overall access to public transportation systems. Barriers such as inefficient lifts and ramps, inaccessible platforms, inadaptable bus stops, inexistent stop announcements or route identifications (Bezyak et al., 2017) directly impact the ability of people with disabilities to fully experience the social, economic and political environments of their community (Christensen, 2009). Indeed, improving the mobility of PWD gives them autonomy and reduces the risk of social isolation (Simplican et al., 2015).

\section{Mobility as a Service for People with Disability}

Fragnière et al. (2017) defined service as a problem resolution that simplifies and changes the life of the user; it must be designed, pretested, and validated by performance and perception measurements. Mobility as a Service (MaaS) is an attempt to overcome market segmentation by offering transport services tailored to the individual traveller's needs (Becker et al., 2020). Its introduction is a challenge for companies, public authorities, academics and citizens, especially regarding end-user acceptance such as usefulness, ease of use and security perception (Ramseyer et al., 2018).

From a user perspective, MaaS is described as an alternative to the usage of private vehicles. It is characterised by door-to-door convenience with easy, integrated, and multi-modal travel. Its ease of payment is done through technological connectivity and functionalities, particularly by mobile devices (Lyons et al., 2019). For Hietanen (2014), the MaaS goal is to create a cooperative, interconnected eco-system of transportation that provides mobility services reflecting the needs of customers. Users can access a single service platform available on demand and incorporating all transport services from cars to buses to rail and on-demand services. For MaaS to successfully expand mobility options for PWD, MaaS developers would need to embrace universal design principles in both customer interaction and vehicle design ${ }^{7}$.

In recent years, alternatives to the existing conventional ways of transportation have emerged as means of transport. Around the MaaS approach, popular providers such as Uber, BlaBlaCar or
DiDi Chuxing, to name a few, are the result of these new mobility concepts. On-demand mobility, as these services are called, refers to the use of shared means of transport available on demand (Greenblatt and Shaheen, 2015). On-demand mobility is an emerging concept, driven by the development of information and communication technologies (ICT), on the one hand, thus enabling a convenient and personalised service, on demand (Xie et al., 2019), and, on the other hand, is a phenomenon of the constantly growing sharing economy (Greenblatt and Shaheen, 2015). The different forms of on-demand services (such as car/ ridesharing, car/vanpooling, ride-hailing) usually have one thing in common: the user logs on to the provider, accesses the offers via a mobile app and selects the most suitable offer, on-demand (Xie et al., 2019).

Public transport is challenging for PWD, who experience issues such as overcrowding, uncooperative staff and unfriendliness of other travellers. ${ }^{8}$ PWD are often confronted with restricted accessibility or the absence of an adequate offer of public transportation services. In an urban context, it is especially difficult for them to cover the first and last mile between the nearest public transportation node and their workplace or home. This can even be one of the main reasons for them not to take public transport at all (Wang and Odoni, 2016). This challenge is well-known in the scientific literature and concerns the first-mile and last-mile transport (FMLM transport) that "combines services, which cover the distance between the ultimate start and ultimate destination of a journey, by bridging the distance between the last transportation hub, like a bus or tram stop, closest to the ultimate start or end of a journey" (Ruscher et al., 2018, p. 200).

Many cities struggle with finding solutions combining accessibility, affordability, and availability that meet the needs of different user groups. Ruscher et al. (2018) analysed the current FMLM mobility offer in the cities of Vienna and Zurich and deduced five action areas to improve the situation: 1. Expansion of service areas for mobility services, 2. Establishment of ondemand services, 3. Improvement of service accessibility, 4. Integration of medical shuttle services into the public transport system and 5. Policymaking for a suitable framework. To sum up, by integrating mobility services that are designed in an 1) accessible way for the different user groups, that are 2) available, e.g., by offering on-demand services and that are 3) affordable by integrating them into the public transport system, a smart transportation system solving the FMLM challenge could be established. As to the accessibility issue, the transport offers should not only be accessible physically but also virtually, meaning that the booking system is centralized and accessible for everyone.

\section{Autonomous Vehicles for People with Disability}

Emerging transportation technologies, such as autonomous vehicles (AVs), seem to be promising to contribute to the 
social inclusion of PWD, at least from a mobility point of view. Indeed, AV technology is becoming one of the most promising alternatives to improve mobility for PWD (Hwang et al., 2020). AVs will give new mobility opportunities for PWD who cannot or will not drive (Bradshaw-Martin and Easton, 2014; Darcy and Burke, 2018). However, AVs could present problems to PWD and require assistive technology (Alves, 2017; Nakamura and Ooie, 2017).

Technology could indeed be a facilitator in customizing services and rendering mobility more accessible. AVs are currently tested in different countries, such as Switzerland, Sweden, Germany, Japan or Singapore. Research on AVs mainly focuses on technological aspects. Some studies deal with public AVs and passengers' acceptance in general (Eden et al., 2017; Ramseyer et al., 2018). Another study deals with the potential of AVs for tourism destinations and the elements that could hinder a destination from integrating them (Grèzes et al., 2018).

While Autonomous vehicles (AVs) represent a technological revolution in the transportation sphere, their efficient and orderly introduction require their acceptance by the public (Bennett et al., 2019). To deal with PWD's acceptance of AVs, it is useful to consider the interaction between PWD and AVs as a service encounter between a customer and a server, where technology plays an important role in assisting both the customer as the server. Froehle and Roth (2004) discuss five possible modes of service encounters, from technology-free customer contact to technology-generated customer service, or self-service. This last mode corresponds to the AVs concept. In the absence of a server, the control is shared between the $\mathrm{AV}$ and the customer. Therefore, it is important to explore further the extent to which control, perceived or actual, influences the customer's adoption, use and commitment to AVs.

Bennett et al. (2019) observed how people with intellectual disabilities perceived the use of AVs. For the authors, access to user-friendly and equitable transportation is a major factor influencing the health and well-being of people with mental disabilities, and AVs have much to offer to intellectually vulnerable travellers. They also found that three categories of attitude towards AVs emerge: freedom, fear and curiosity.

\section{Designing for All Through Universal Design and Inclusive Design}

"Universal design means the design of products, environments, programmes and services to be usable by all people, to the greatest extent possible, without the need for adaptation or specialized design" (Ostroff, 2011). Universal design aims to simplify life for everyone by designing goods, services or buildings that are accessible and usable (Darcy et al., 2010). Universal design is based on seven principles: 1) Equitable use, 2) Flexibility in use, 3) Simple and intuitive use, 4) Perceptible information, 5) Tolerance for error, 6) Low physical effort and 7) Size and space for approach and use. These principles are expanded in a set of guidelines (Story, 2011). Universal design helps address the complexity and diversity of disability considering the different abilities, level of support the individual needs and methods of communication (Dickson et al., 2016). To be accessible, the design of a mobility service must respect these seven principles and their associated guidelines.

While universal design is one-size-fits-all, inclusive design is one-size-fits-one (Holmes, 2020). Inclusive design is part of a "recent international trend towards the integration of older and disabled people in the mainstream of society" (Clarkson et al., 2003). Indeed, inclusion can be a source of innovation and growth. It can be a catalyst for creativity and an economic imperative. An inclusive environment considers the psychological and emotional impact on people. Inclusion needs practice and takes time to develop; the work of inclusion is never done. There are no single answers that suit everyone, but we can adapt the solutions to what people need (Holmes, 2020). Inclusive Design can act as a spur to innovation. There is a strong social case for inclusive design based on the desirability of social cohesion and inclusivity and the accessibility of public buildings, spaces and services, which can promote social inclusion (Clarkson et al., 2003). Better design of mainstream products and services can lead to considerable market and brand advantage. This is also the case for mobility services.

\section{METHODOLOGY}

The main methodology used in this research is the qualitative survey based on semi-structured interviews. Indeed, the topic of an AV experience is not yet known, so we proceeded with an exploratory study. In this context, the goal of the interviews is not to be representative and to collect enough quantitative questionnaires to then make inferences (draw conclusions about the studied population from a random sample). As this type of AV experiment is completely new, we conducted semi-structured interviews with eight targeted profiles; interviews contained open-ended questions and lasted between 60 and $90 \mathrm{~min}$. Rather than being representative, the goal is to do an in-depth exploration. The research philosophy here is interpretivism as opposed to positivism. As researchers, we will wear "our glasses" to interpret the world in our own way.

This fieldwork and the related questionnaire are based on a service design methodology developed at the Tourism Institute of the University of Applied Sciences Western Switzerland (HES-SO Valais-Wallis). The logic of these open questions that are typical of service design enables us to better understand the experience of users by analysing their perceptions and behaviour throughout their mobility customer journey, starting from the pretransaction phase (before their travelling experience), to their transaction phase (the travelling journey itself), and the posttransaction phase (after their travelling experience).

The questionnaire is presented in the following form:

- Question 1: Describe the journeys you make on an ordinary day.

- Question 2: Explain your last trip on public transport.

- Question 3: Generally speaking, what are your daily and weekly mobility needs? 
TABLE 1 | List of interviewees.

\begin{tabular}{|c|c|c|c|}
\hline ID & Gender identity & Characteristics & Concerned disability \\
\hline 1 & Man & PWD (wheelchair) & Mobility \\
\hline 2 & Woman & PWD (glasses and blind cane) & Visual impairment \\
\hline 3 & Man & Carer for PWD & Intellectual disability \\
\hline 4 & Woman & PWD (crutches and adapted car) & Mobility \\
\hline 5 & Woman & Carer for PWD & Intellectual disability \\
\hline 6 & Man & PWD (wheelchair and adapted car) & Mobility \\
\hline 7 & Woman & Carer for PWD & Intellectual disability \\
\hline 8 & Man & PWD (wheelchair and adapted car) & Mobility \\
\hline
\end{tabular}

Imagine a fully autonomous public transport vehicle equipped to transport you without a driver from your home to the city centre or train station.

- Question 4: To what extent would you be tempted to use it?

- Question 5: What would be the barriers (or constraints) to using it?

- Question 6: What are the minimum requirements for you to try it (adoption criteria)?

- Question 7: What is your opinion on autonomous vehicles?

- Question 8: Would you use them in addition to another means of public or private transport?

- Question 9: What is your view on assistive technologies?

- Question 10: How do you feel when travelling by public transport?

- Question 11: How much effort do you need to make when travelling by public transport?

- Question 12: Give me three words to define a public transport trip in an autonomous shuttle.

- Question 13: Do you see any advantages or opportunities in this mode of transport?

- Question 14: Do you feel included in society?

- Question 15: If you had a magic wand, what would you like to change about the current state of public transport?

- Question 16: Are there any other topics or questions you would have liked to discuss during our interview?

Five PWD, physical or psychological or both, were interviewed (see Table 1 above). Three interviews were done with people accompanying people with mental disabilities. These interviews are quite long and require a lot of knowledge from the interviewer. Indeed, it is a question of accurately restoring perceptions linked to a context of experience the respondents have probably never had (for example, travelling in an autonomous shuttle). To do this, the interviewer adds a series of sub-questions to the main questions so the respondent can project himself/herself into this type of new service experience. This interview technique is called the "what-if" technique.

All interviews were recorded, then transcribed word for word. Once the database is complete, in our case, a narrative file of about 50 pages, we use the NVivo software to create a synthesis of the results. The principle is as follows. All questionnaires are read in detail once. Then, based on the review of the scientific literature, themes or keys are chosen to categorize all the contents of the transcripts. For each theme, the related verbatims or quotations can be precisely recorded. This allows us to build a synthesis of the results. At this level, no interpretation is made by the researcher.

From the synthesis of the results, a discussion is developed by the authors of the article, the objective being to provide meanings to the social phenomena identified in the synthesis. This will allow us to produce research propositions. In our case, the discussion proposed in Section 4 presents a whole series of precepts based on our research propositions. In Section 5, these precepts are translated in an integrative model to facilitate the design of the AV experience for PWD.

\section{FINDINGS}

The semi-structured interviews revealed various social phenomena that are discussed in this section and structured around the following themes:

- Accessibility issues concern all of us

- Mobility is more than means of transport

- Special needs for mobility

- Pros and cons of AVs for PWD

Some findings concern mobility of PWD in a general matter and their perception of mobility services. Although they are not focused on AVs in particular, their implications on the design of a mobility service provided by an AV are of first importance. Indeed, the technology-in our case AVs-is solely the means to reach the goal, the mobility of PWD to foster social inclusion.

\section{Accessibility Issues Concern All of Us}

Disability, whether mental, physical or both, affects the mobility of PWD. Mobility can thus become a real ordeal for PWD. Indeed, travels from point A to B for a PWD are complicated by obstacles such as narrow pavement, steep slopes, parking difficulties, inadequate infrastructures and facilities and incomprehensible information. The disability itself causes an impossibility to use public transport; an interviewee reported, "in our institution, a resident with autism is picked up by a taxi because taking public transport is too difficult for him". Despite the difficulties endured by PWD, citizens are extremely well served with public transportation in urban agglomeration settings, allowing them to travel by tramways quickly and 
without difficulty to city centres. However, the situation differs in peripheral, sparsely populated and dispersed areas, where public transportation is not adapted for PWD, adding deficiencies in the use of new technologies to their travel difficulties. Additionally, frequently encountered problems in train stations, such as accessibility to facilities, parking, platforms or ticketing machines, are reported by PWD. "In general, I am quite disappointed with public transport. First, they must make parking spaces where the transport leaves, not that you must walk for miles". It may deter them from travelling at all, thus threatening them with increasing isolation and exclusion. To avoid such consequences, PWD in peripheral regions often prefer to use private vehicles for more independence and flexibility. "I normally use the car, because it is much more convenient, and I am much more independent. It's easier with timetables". While public transportation systems have introduced several infrastructures to facilitate the travel of PWD, accessibility problems also affect other population groups such as people with sensory or mental disabilities, those with reading problems, symbolisation and spatio-temporal location difficulties, those with the inability to memorise, communicate, or manage unexpected situations, and even children, elderly people, pregnant women and parents with pushchairs. In other words, accessibility affects everyone at one time or another.

\section{Mobility is More than Means of Transport}

While comfort, journey duration, security, accessibility to trains from platforms and timetables are all important examples of touchpoints in the choice of public transportation, these salient attributes for the attractiveness of public transport are not the only decision criteria. One of the main problems is situated before arriving at the station (bus or train). For a person with a physical disability, there is a whole logistics element to anticipate getting to the station on time and in good condition. "For my car, I always need a car park, where I can open the door fully". "The access to the train station and to the platform were not adapted, too steep, too narrow, not thought out for disabled people. It's a bit of an obstacle course". Unlike people with no disabilities, who move from point A to point B without difficulty, PWD have to make extra efforts while travelling, thus inducing a certain amount of anxiety. "We are experts in anticipation". Prior to travelling, they ask themselves several questions such as: Who will I come across? How will the journey to the station go? Is there going to be traffic? Will I be on time? Will I cross the road? Will there be a lot of noise? Will there be traffic lights? Will I miss the train or the bus or the connections? Consequently, because PWD must prepare in advance and think about the logistics and possibilities that an unexpected event might occur, their journey is much more complicated, is a very different process to consider, and point $\mathrm{B}$ is much further away than it is for those without disabilities.

\section{Special Needs for Mobility}

A person with physical disabilities will be concerned more about the logistics aspect before the actual boarding, such as traffic jams, traffic deviation, available and well-positioned parking space, distance from the ticket machine to the car, and toilet facilities. A person with mental disabilities will instead deal with psychological issues such as fear and anxiety. "For example, in the group I work with, out of eleven, only one hangs the bus by himself. All the others could not, because there are too many environmental factors that could prevent them from doing so". Furthermore, people with mental disabilities often suffer from motor disorders. Before starting the journey, these possible issues cause stress to the PWD. In long-distance rail traffic, as well as bus, tram, boat and cable car transport, accessibility for PWD is still only possible to a limited extent. However, there are always staff on site (or on reservation) in these cases responsible for ensuring that PWD board or disembark safely.

Similarly, during the journey, a person with physical disability will have difficulty fully enjoying the experience for the same reasons. Often they encounter problems with the toilets and other onboard facilities, and because of their mobility problems, they might have to stay still for long hours. "Toilets that are not suitable can turn an experience into a nightmare". On the other hand, people with mental disabilities often have to experience the fear, oppression and anxiety of unpredictable situations, like talking to strangers, crowd movements, or unfamiliar devices like door or toilet handles. Furthermore, once on board, besides strong feelings about stress they have undergone before and during the travel experience, they might be anticipating the return trip with the same difficulties and anxieties.

\section{Pros and Cons of AVs for PWD}

Whereas PWD living in peripheral regions are likely to be more unfamiliar with new technologies, as is often the case among older people, people living in urban areas have already experienced AVs. Indeed, as an interviewee mentioned regarding the metro M2 in Lausanne in Switzerland: "It has existed in Lausanne for many years, and I believe that people living in Lausanne are not dead from having used the M2". The fact that an AV can run on narrow streets otherwise inaccessible to persons with physical disabilities is perceived as great progress towards mobility. "AVs are interesting to get around the city in places where public transport does not normally go, such as the city centre, places with difficult access such as slopes, cobbles". However, the idea that the AV might brake violently is a safety concern for PWD. "How will I be able to buckle up and feel safe if suddenly there is emergency braking?" The absence of staff in the AV is also seen as detrimental to the quality of public service in that it fosters a feeling of insecurity and complicates the task of users, as the userfriendliness or convenience for people with special needs are not fully developed yet. "The condition to use an AV would typically be accessibility, as there is no driver to help me get the ramp out". In summary, curiosity towards acceptance of new technologies is present. However, criteria such as unrestricted use, cost and safety are major drivers towards their adoption. The most important thing for PWD is less a question of the vehicle's autonomy than a question of trust about the guarantee of safety for independent access while allowing enough time to go out and come back in. This is seen as a major stress factor. PWD are dealing more and more with automatic or semi-automatic devices. New technologies can surely help and come into assistance for PWD. An AV travelling door to door and on-demand will 
indeed enhance mobility for PWD or those with any special needs who are willing to pay for such a service. "If an AV on demand goes past my house to take me to my destination, yes, I would use it. But it must go past my house, door-to-door".

Regardless of the type of disability, the enormous physical and intellectual effort required, accompanied by exhaustion, can destroy a travel experience. As a result, preparation and learning are needed over a long period before AVs can be adopted and used by PWD. Therefore, it is first important that PWD have access to information that is as clear and easy to understand as possible. Indeed, PWD "always have to anticipate, and that requires organisation". Like everyone else, they can do many things independently if they get the right help and information. It would help to adopt AV. "I think a lot of people will like it because you're not dependent". People with intellectual disabilities sometimes find it more difficult than others to understand and learn new things, but with clear and adapted information, they can be better included in social life and participate in activities around them. Creating clear information means creating information that is easy to read and understand. PWD know better than others what their needs are, what is useful for them, and what kind of information they need. Those processes should include the participation of PWD at some point. Therefore, technical assistance must take all these factors into account to be as adapted as much as possible to the person to not be stigmatised.

\section{INTEGRATIVE MODEL TO ORCHESTRATE THE DESIGN OF AVS EXPERIENCE FOR PWD}

Fieldwork research methods and tools were used to reveal users' experiences, while content analysis discovered meaningful insights regarding the opportunities for the better quality of life of PWD. The in-depth and contextualised findings from the qualitative data were used to formulate an integrative model to orchestrate the design of AVs experience for PWD. As the first step of this integrative model, we propose immersion in the future AVs site to highlight the key factors of the design of the AVs experience. Then, the qualitative and descriptive elements were transposed in a service blueprint creating the conceptual image of the integrative model by visualizing the relationships between different service components and touchpoints. As the third step of this integrative model, we use service design methodology to orchestrate the customer journey for better AVs experiences for PWD. Finally, policy recommendations are made to design universal AV experiences.

To illustrate the application of this integrative model, we use the case of the city of Sion in Switzerland. Indeed, since 2016, AVs have been tested on two routes, one between the train station and the old town, the second in the old town. During this first test, no special attention was given to PWD. In 2021, a new route is planned in Uvrier, a residential quarter of Sion. On this new route, on-demand service and first-mile, last-mile service (FMLM) will be tested. Furthermore, a focus will be given to the needs of PWD.

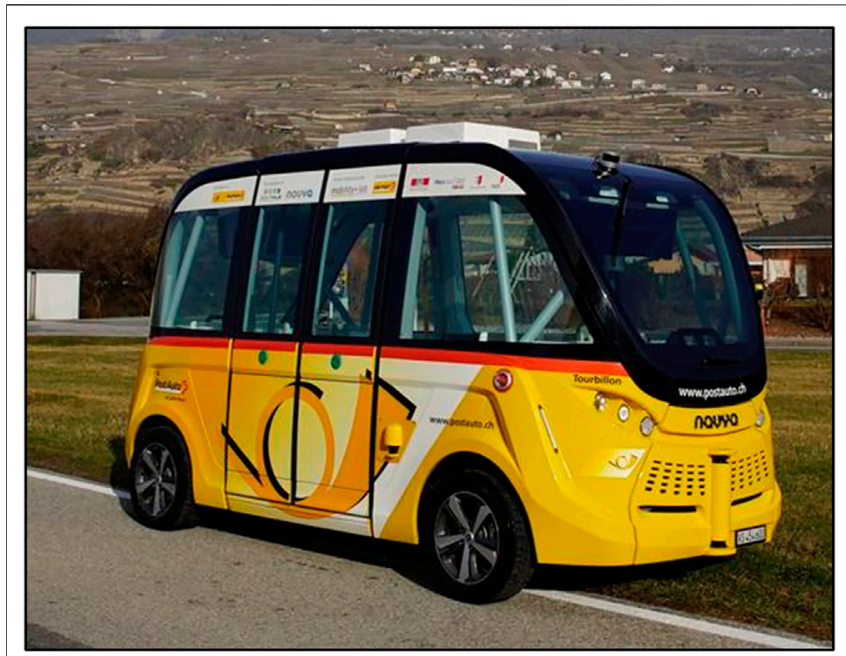

FIGURE 1 | AV operating in Uvrier, a residential quarter of the city of Sion (Switzerland).

The AVs service in Uvrier is organised as follow. Two AVs (see Figure 1) are operating in the residential quarter. In each $A V$, due to the Swiss law, a groom is on board to ensure safety. For the test period (April to October 2021), the service is free of charge. As it is an on-demand service, users book an AV through a dedicated smartphone application, an avatar screen located in the train station (see Figure 2), or phone.

\section{Immersion in the Future AVs Experimentation Site}

To prepare this new route in Uvrier, an on-site immersion was done by the research team. This immersion was conducted as an audit. The universal design principles were used as criteria to evaluate the perceived touchpoints. The audit process consists of five steps: 1) the perceived touchpoint is described, 2) an illustration (e.g. photo) is made, 3) the touchpoint is evaluated (good, neutral, or bad), 4) the evaluation is linked to a universal design principle and 5) a recommendation for the implementation is made. To illustrate how the audit was conducted, three examples of touchpoints and recommendations are mentioned in the immersion template (see Figure 3). This audit enabled the team to contextualise the findings of the qualitative study and test design solutions beforehand for the actual implementation of such a new service.

\section{Service Blueprint of the AV Experience of PWD}

The service blueprint is a matrix organised in two dimensions. The first horizontal dimension represents the time flow of a service experience. In particular, the service blueprint is divided into pre-transaction, transaction and post-transaction, with the idea that the user journey exists before a service transaction. This is the case of a PWD who eats lunch at home before taking public transport (in this case, the transaction). Similarly, once the 

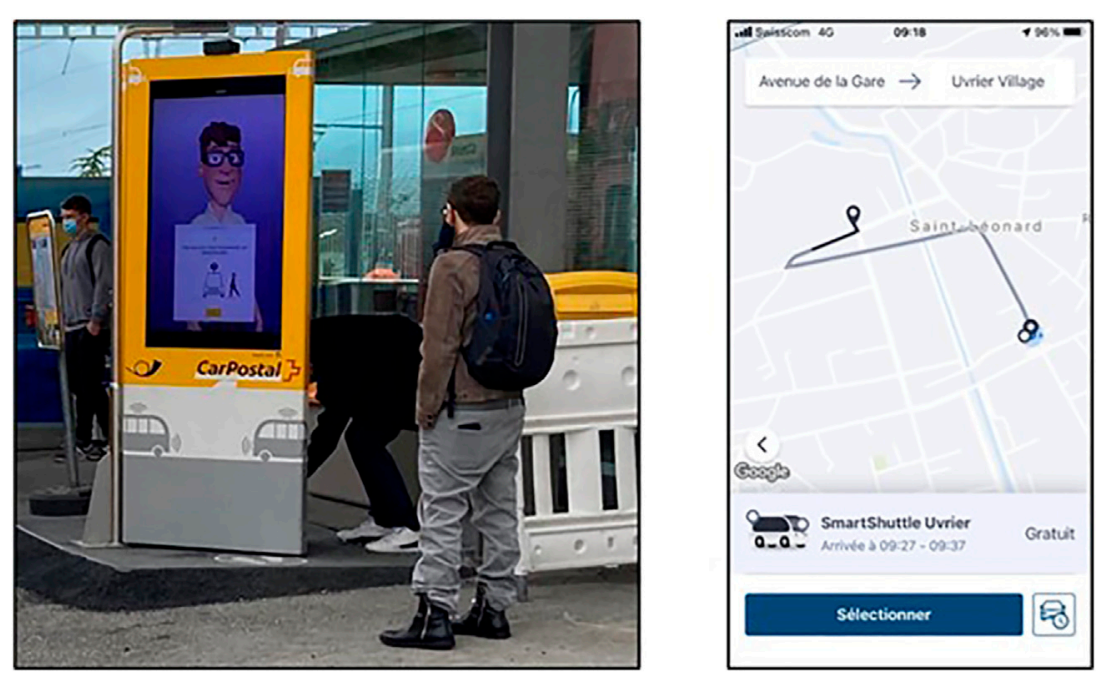

FIGURE 2 | Avatar screen and smartphone application to book an AV.

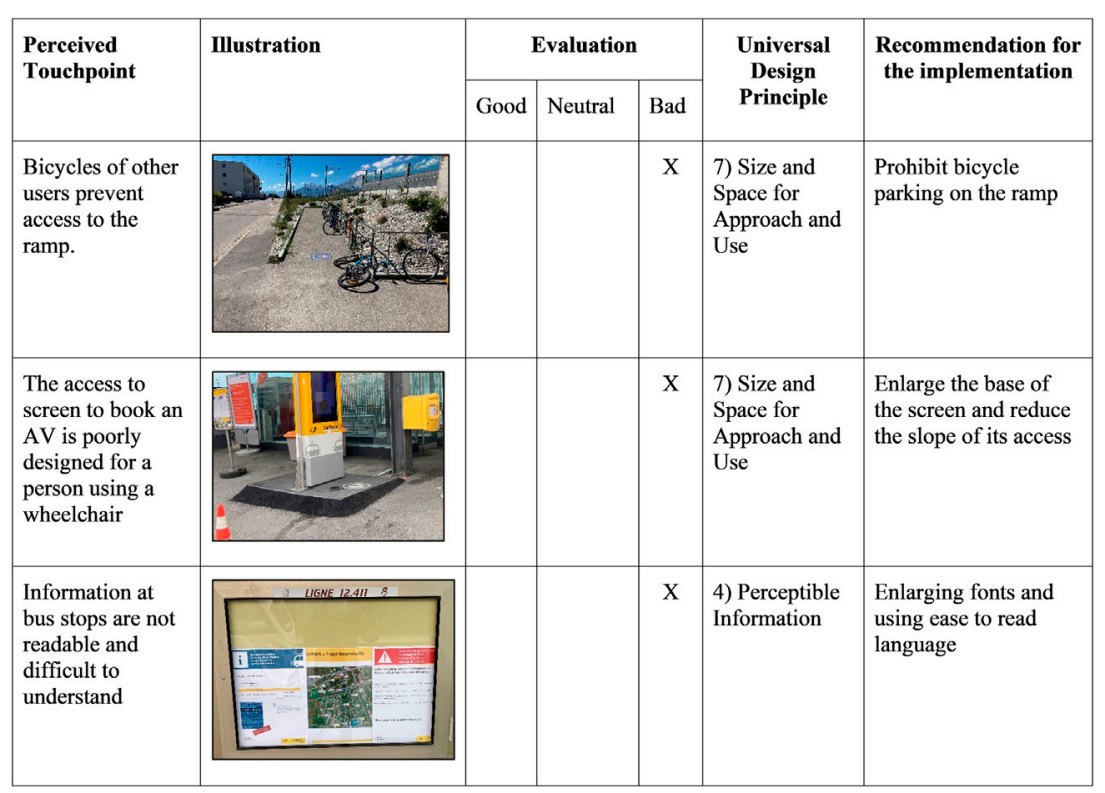

FIGURE 3 | Three examples of touchpoints and recommendations.

transaction is completed (in our case, the PWD takes the autonomous shuttle from point $\mathrm{A}$ to point B), the blueprint integrates a post-transaction that allows the user to make the link with his journey and do other activities, such as meeting a friend.

The other vertical dimension is linked to the different interactions between the actors in the service experience. Indeed, in service production, we consider the user the coproducer of the service. In our case, the $\mathrm{AV}$ is the service provider. The user waits for the AV at the stop. As soon as it arrives, he enters and sits down. He thus co-produces the service. Thus, the blueprint integrates several lines of interaction. The customer actions line corresponds to the user journey and is structured in steps. The employee visible actions line corresponds to the touchpoint provided by the AV and the groom. It can be first the purchase of the ticket at a terminal next to the shuttle stop. Then, the touchpoint can be the groom who welcomes the passenger and helps him get into the vehicle. Under is the line of visibility. Above is everything that is visible to the user. Below, we find what we could call the back office, with, for example, cleaning operations of the AV and all the interactions the provider can have with suppliers, such as the maintenance and repair of the AVs.

The service blueprint below illustrates the pre-transaction phase (until the arrival at the shuttle bus stop), the transaction 


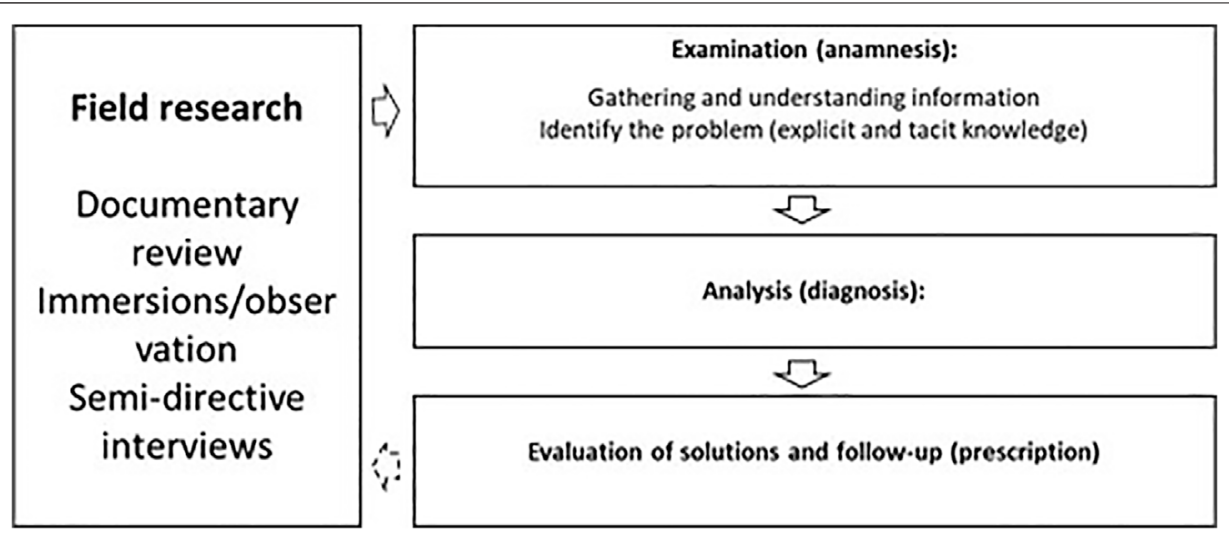

FIGURE 4 | Service Design methodology as a scientific approach for evidence-based user experience designs.

(boarding, onboard and disembarking) and the post-transaction (leave the shuttle premises, evaluation of experience). Five actors are involved: the customer (user), the Smart Shuttle, the groom, Car Postal and the city of Sion. We highlighted the problems, risks and positive aspects.

Based on our immersion and interviews, we have produced a service blueprint (see below) of the future AV service to be implemented at Uvrier (Switzerland). The goal of this blueprint is to describe and draw an experience of AV service as it could be generalized in the future. It gives an overview of the propositions made by our users: autonomy (e.g., ensure the autonomous access to the AV), access (e.g., automatic ramp), signage (e.g., warning sounds), automatic stop (attention to ensure the correct timing, allowing users to embark and disembark independently when the shuttle is fully autonomous) and stop on demand (attention to ensure the correct timing, allowing users to embark and disembark independently when the AV is fully autonomous, for visually impaired people, the shuttle must stop at the same place). On the service blueprint, major risks were identified (e.g., glare affecting visually impaired and blind people due to large windows, lack of ground markings for blind people, difficult, even impossible, the transition between train and shuttle due to the non-adaptation of the station). The service blueprint allows upstream, in the design phase, to project oneself in an experience of AV service and to consider these elements of risk, problem and potential directly linked to the PWD. The advantage of this approach is to be directed, as indicated in the literature review, by a logic of universal design and inclusive design and thus to favour the inclusion of all people. For example, in the fieldwork, we clearly identified that people with mental disabilities can have sudden fears when getting into the vehicle. Knowing this, we can, for example, ask the groom to reassure a first user-with or without disability.

While comfort, journey duration, security, accessibility to platforms and timetables are all important examples of touchpoints in the choice of public transportation, these salient attributes for the attractiveness of public transport are not the only decision criteria. One of the main problems is situated before arriving at the station (bus or train). For a PWD, there is a whole logistics element to anticipate getting to the station on time and in good condition. A PWD will be concerned more about the logistics aspect before the actual boarding, such as traffic jams, traffic deviation, available and well-positioned parking space, distance from the ticket machine to the car, and toilet facilities A person with a mental disability will rather deal with psychological issues such as fear and anxiety.

We identified the following problems based on our fieldwork: access to the smart shuttle (e.g., ramp, bus stop), reachability of the equipment in the smart shuttle (e.g., the emergency button), security (e.g., missing system to tie up and secure the wheelchair, retaining straps), autonomy (getting on and off the shuttle independently), communication (e.g., lack of information, such as shuttle number, position, route, next stop) and signage (e.g., warning sounds).

Positive aspects we identified based on our fieldwork are the following: presence of the groom (e.g., help, information, reassurance, adaptation of the bus stop), layout of the shuttle (e.g., windows for scenery, comfort), access to hardly accessible places (e.g., steep roads, irregular surfaces, paved streets) and social inclusion (e.g., meeting and talking to other passengers).

\section{Service Design Methodology to Orchestrate the AVs User Experiences for PWD}

Our service design methodology (see Fragnière et al., 2012) is a scientific approach for evidence-based user experience designs (see Figure 4). This validation process is like a patient's visit to the doctor in three stages: examination, diagnosis and prescription. The examination, including the anamnesis (analysis of the initial situation), consists of gathering and understanding information to identify the problem (explicit and tacit knowledge). Diagnosis (inventory and mapping, problem modelling) corresponds to the analysis phase. The ideas generated are evaluated in order of priority based on local constraints to formulate the ideal solution. The result is a list of possible innovative conceptual recommendations. If solutions are still not found or if another problem arises after evaluating the solution, the problem-solving process starts again in the first step to redefine the initial situation (iterative process).

The case of the Uvrier AV is particularly interesting since it represents a pilot project from which general precepts will be derived for improving mobility for PWD. To do this, we conducted immersion sessions to evaluate the readiness of the 


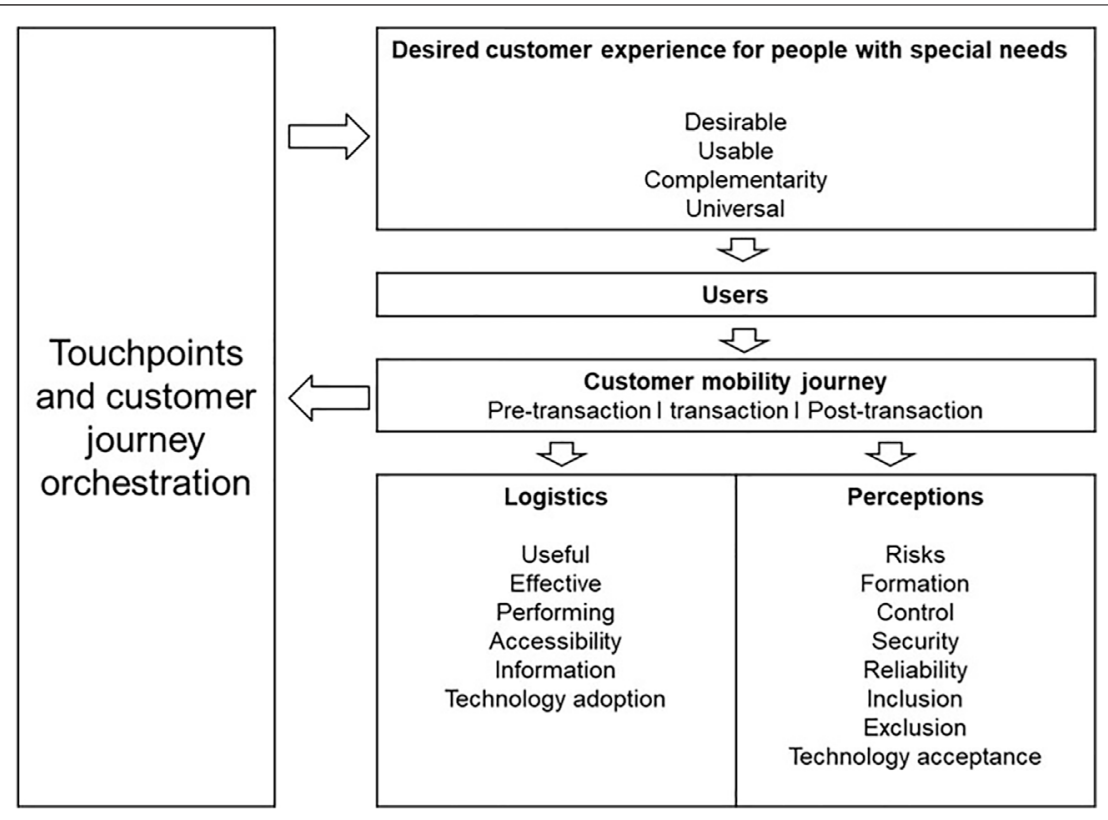

FIGURE 5 | Touchpoints and customer journey orchestration into customer experience.

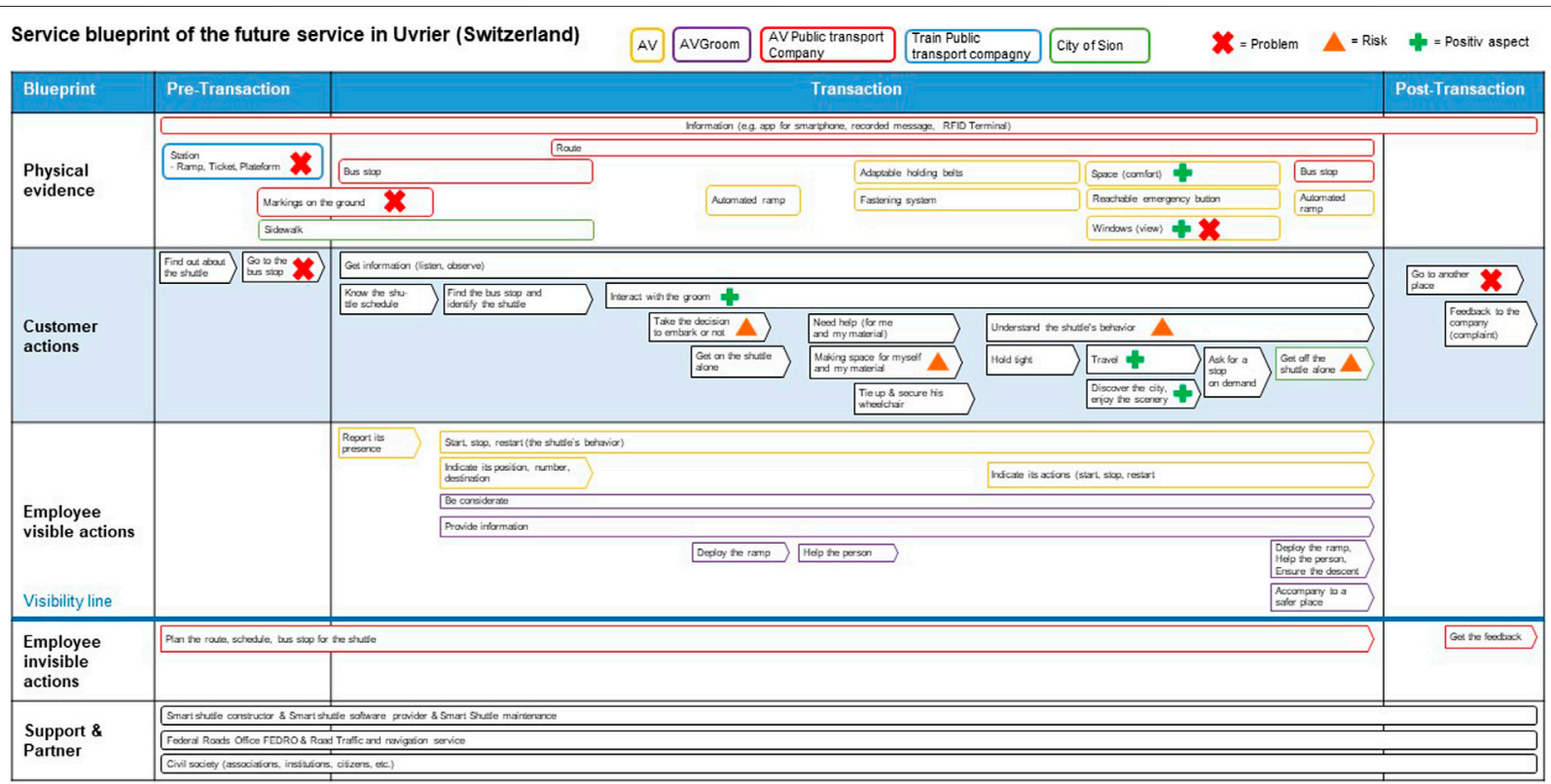

FIGURE 6 | Service blueprint of the future service in Uvrier (Switzerland).

future to deliver the new service in a residential setting and interviewed eight potential users with special needs, as well as those working with them, to collect their perceptions and feelings. The data collected provided information on users' perceptions such as usefulness, efficiency, safety, comfort and usability. In addition, the results reveal new insights, including problematic links between users' experiences, risk perceptions, the acceptability of new technology and views regarding inclusion in society. This study focuses mainly on identifying these different attributes identified in the field research. The results will be exploited in future research to improve the operating modes of this new type of mobility service for people with special needs.

Fieldwork research has been completed and allowed a very rich and detailed data collection. It enables us to produce a service blueprint adopting the principles of universal design. Unfortunately, in this COVID period, real-life testing of the 
design was not possible. We created a model (see Figure 5 to implement the recommendations presented in the service blueprint (see Figure 6). In this model, the notion of orchestration is of first importance. Indeed, to have an impact on PWD (desired customer experience), all touchpoints of the customer journey must be taken into account.

\section{Policy Recommendations for Universal and Inclusive AV Experiences \\ Never for us Without us}

As a first recommendation, policymaking processes must include PWD to design the user experience. Especially for these users, for is not sufficient. with is primordial. Therefore, the service design methodology enables researchers, designers as well as policymakers to work with PWD during the whole process. The field research enables the collection of their needs. Then, the user experience is scripted in a service blueprint. Based on this, the user experience of the AVs is tested with PWD to enhance the service before its public launch.

\section{Universal Design and Inclusive Design Principles}

Usually, service designs remain linked to the notion of persona used in the marketing of experience. This causes extreme customer segmentation and could lead to huge exclusion problems to the point that some people feel excluded due to the development of new products and services. For example, smartphone applications allowing the purchase products and services also contributed to digital dive phenomena among the population, a problem faced by older as well as young people. As technology for MaaS, AVs could also lead to exclusion. To avoid this situation, universal design principles must be used to design the user experience and include the needs of the whole population. As well, inclusive design principles, like "solving for one, extended for many" (Holmes, 2020), could also bring elements specifically designed for PWD, which will benefit the entire population.

\section{CONCLUSION}

The mobility of people is one of the most important elements promoting their inclusion in society. If mobility policy is poorly designed, PWD risk being excluded from the social cohesion that is the necessary cement of our societies International, national and regional laws require that all measures are taken to ensure equal treatment for PWD in the public transport domain. Switzerland, with its monistic view of the law, has ratified these international agreements but has been slow to put them into practice.

As part of this applied research, we used semi-structured interviews and immersions to examine the daily mobility of PWD in-depth. After analysing our collected data, we find that too little is done at the regional and city level to help PWD. In general, public transport is concentrated only on the main routes and rarely on the so-called FMLM (First Mile, Last Mile). It is on the latter aspects that PWD lack real support from public authorities. These findings seem obvious, but there is a true lack of awareness at this level. Our findings regarding the perception of PWD on AVs are contrasted. As a new assistive technology, AVs could herald an advance in the mobility of PWD. However, AVs could also add risks and constraints for them, especially if the design of the new mobility service does not follow universal and inclusive design principles.

Based on these findings, we propose an integrative model to orchestrate the design of AV experience for PWD. The integrative model sketches out concrete solutions through immersion, service blueprints and service design methodology to orchestrate the AV user experiences for PWD. To illustrate the application of this integrative model, we use the case of the city of Sion in Switzerland, where AVs have been tested since 2016. Especially, we focused on the new route planned in Uvrier, a residential quarter of Sion.

The integrative model also presents policy recommendations for universal and inclusive AV experiences. Indeed, for this research, we worked directly with PWD and created universal and inclusive designs for AVs. We respected the motto "never for us without us". As researchers and designers, we are not allowed to design for them without co-creating with them. Another lesson learned from this research on AVs is that unfortunately, the digitalisation of services remains a goal that serves most of the population but forgives the ideal of inclusion of the whole population.

In further research, we intend to complete the approach envisaged in the project framework and test these solutions on a full scale. For the best, we would like to implement an inclusive and universal on-demand FMLM service with AVs at the regional level to enhance mobility for all and foster social inclusion.

\section{DATA AVAILABILITY STATEMENT}

The raw data supporting the conclusions of this article will be made available by the authors, without undue reservation.

\section{ETHICS STATEMENT}

Ethical review and approval was not required for the study on human participants in accordance with the local legislation and institutional requirements. Written informed consent for participation was not required for this study in accordance with the national legislation and the institutional requirements.

\section{AUTHOR CONTRIBUTIONS}

$\mathrm{BN}, \mathrm{RR}$, and EF contributed to conception and design of the study. BN, RR, SG, MW, AG, and DJ performed the interviews and wrote sections of the manuscript. $\mathrm{BN}, \mathrm{RR}$, and $\mathrm{EF}$ wrote the first draft of the manuscript. BN, RR, and EF contributed to the manuscript revision, read, and approved the submitted version.

\section{FUNDING}

This research was funded by DESIGNSCAPES (Building Capacity for Design-enabled Innovation in Urban 
Environments) is a H2020 European project approved under the topic CO-CREATION-02-2016- User-driven innovation: value creation through design-enabled innovation. The research team

\section{REFERENCES}

Alves, M. (2017). Driven by Distraction: Sustainable Road Safety and the Impact of Autonomous Driving on Vulnerable Users (Breakout Presentation). J. Transport Health 7, S65. doi:10.1016/j.jth.2017.11.105

Becker, H., Balac, M., Ciari, F., and Axhausen, K. W. (2020). Assessing the Welfare Impacts of Shared Mobility and Mobility as a Service (MaaS). Transportation Res. A: Pol. Pract. 131, 228-243. doi:10.1016/j.tra.2019.09.027

Bennett, R., Vijaygopal, R., and Kottasz, R. (2019). Attitudes towards Autonomous Vehicles Among People with Physical Disabilities. Transportation Res. A: Pol. Pract. 127, 1-17. doi:10.1016/j.tra.2019.07.002

Bezyak, J. L., Sabella, S. A., and Gattis, R. H. (2017). Public Transportation: An Investigation of Barriers for People with Disabilities. J. Disabil. Pol. Stud. 28 (1), 52-60. doi:10.1177/1044207317702070

Bradshaw-Martin, H., and Easton, C. (2014). Autonomous or 'driverless' Cars and Disability: A Legal and Ethical Analysis. Eur. J. Curr. Leg. Issues 20 (3).

Christensen, K. M. (2009). Socially Equitable Community Planning: Including Individuals with Disabilities in the Democratic Association of Place. Review of Disability Studies. Int. J. 5 (3), 49-52.

Clarkson, P. J., Coleman, R., Keates, S., and Lebbon, C. (2003). Inclusive Design: Design for the Whole Population. London: Springer-Verlag. doi:10.1007/978-1-4471-0001-0

Daniels, M. J., Drogin Rodgers, E. B., and Wiggins, B. P. (2005). “Travel Tales”: An Interpretive Analysis of Constraints and Negotiations to Pleasure Travel as Experienced by Persons with Physical Disabilities. Tourism Manage. 26 (6), 919-930. doi:10.1016/j.tourman.2004.06.010

Darcy, S., and Buhalis, D. (2010). "Chapter 1. Introduction: From Disabled Tourists to Accessible Tourism," in Accessible Tourism: Concepts and Issues. Editors D. Buhalis and S. Darcy (Bristol, Blue Ridge Summit: Channel View Publications), 1-20. doi:10.21832/9781845411626-004

Darcy, S., and Burke, P. F. (2018). On the Road Again: The Barriers and Benefits of Automobility for People with Disability. Transportation Res. Part A: Pol. Pract. 107, 229-245. doi:10.1016/j.tra.2017.11.002

Darcy, S., Cameron, B., and Pegg, S. (2010). "Chapter 15. Developing a Business Case for Accessible Tourism," in Accessible Tourism: Concepts and Issues. Editors D. Buhalis and S. Darcy (Bristol, Blue Ridge Summit: Channel View Publications), 241-259. doi:10.21832/9781845411626-018

Dickson, T. J., Darcy, S., Johns, R., and Pentifallo, C. (2016). Inclusive by Design: Transformative Services and Sport-Event Accessibility. Serv. Industries J. 36 (11-12), 532-555. doi:10.1080/02642069.2016.1255728

Eden, G., Nanchen, B., Ramseyer, R., and Evéquoz, F. (2017). "Expectation and Experience: Passenger Acceptance of Autonomous Public Transportation Vehicles," in IFIP Conference on Human-Computer Interaction, 16th IFIP TC 13 International Conference, Proceedings, Part IV, Mumbai, India, September 25-29, 2017 (Cham: Springer), 360-363.

Eichhorn, V., and Buhalis, D. (2010). "Chapter 3. Accessibility: A Key Objective for the Tourism Industry," in Accessible Tourism: Concepts and Issues. Editors D. Buhalis and S. Darcy (Bristol, Blue Ridge Summit: Channel View Publications), 46-61. doi:10.21832/9781845411626-006

Fragnière, E., Nanchen, B., and Sitten, M. (2012). Performing Service Design Experiments Using Ethnomethodology and Theatre-Based Reenactment: a Swiss Ski Resort Case Study. Serv. Sci. 4 (2), 89-100. doi:10.1287/ serv. 1120.0008

Fragnière, E., Ramseyer, R., Grèzes, V., Kuonen, P., Nanchen, B., and Sahut, J.-M. (2017). Service Design and Educational Challenges to Foster Innovation in Tourism: the Case of the Swiss Matterhorn Region. Gestion 34 (1), 203-213. doi:10.3917/g2000.341.0203

Froehle, C. M., and Roth, A. V. (2004). New Measurement Scales for Evaluating Perceptions of the Technology-Mediated Customer Service Experience. J. Operations Manage. 22, 1-21. doi:10.1016/j.jom.2003.12.004

Greenblatt, J. B., and Shaheen, S. (2015). Automated Vehicles, On-Demand Mobility, and Environmental Impacts. Curr. Sustain. Renew. Energ. Rep 2 (3), 74-81. doi:10.1007/s40518-015-0038-5 received two grants: feasibility study and prototype. Due to the COVID-19 crisis, the prototype was interrupted before its completion.

Grèzes, S., Fux, M., and Wilk, R. (2018). “The Potential of Public Autonomous Vehicles in alpine Tourism Destinations," in STCB (Smart Tourism Congress Barcelona), Barcelona, 22-23 November 2018.

Hietanen, S. (2014). 'Mobility as a Service' - the New Transport Model. MaaS Finland CEO, ITS Finland. Technical report.

Holmes, K. (2020). Mismatch: How Inclusion Shapes Design. Cambridge, MA: The MIT Press. doi:10.7551/mitpress/11647.001.0001

Hwang, J., Li, W., Stough, L., Lee, C., and Turnbull, K. (2020). A Focus Group Study on the Potential of Autonomous Vehicles as a Viable Transportation Option: Perspectives from People with Disabilities and Public Transit Agencies. Transportation Res. F: traffic Psychol. Behav. 70, 260-274. doi:10.1016/j.trf.2020.03.007

Lyons, G., Hammond, P., and Mackay, K. (2019). The Importance of User Perspective in the Evolution of MaaS. Transportation Res. Part A: Pol. Pract. 121, 22-36. doi:10.1016/j.tra.2018.12.010

Nakamura, F., and Ooie, K. (2017). A Study on Mobility Improvement for Intellectually Disabled Student Commuters. IATSS Res. 41 (2), 74-81. doi:10.1016/j.iatssr.2017.07.002

Ostroff, L. (2011). "Universal Design: an Evolving Paradigm," in Universal Design Handbook (McGraw-Hill Companies), Vol. 2, 34-42.

Ramseyer, R., Cimmino, F., Emery, L., Grèzes, S., Grèzes, V., Nanchen, B., et al. (2018). "November). Using Phenomenology to Assess Risk Perception of a New Technology in Public Transportation the Case of the Autonomous Vehicles as Mobility as a Service (MaaS) in Switzerland," in 2018 3rd International Conference on System Reliability and Safety (ICSRS), Barcelona, Spain (IEEE), 289-293.

Ruscher, S. H., Kofler, A. C., Neumayer, V., and Renat, J. (2018). "March). Moving Ahead: Elaboration on Cumulative Effects on Urban and Suburban Transport Ecosystems by Enhancing Last Mile Mobility of Older Adults and Persons with Disabilities," in International Conference on Information and Communication Technologies for Ageing Well and e-Health, 4th International Conference, ICT4AWE 2018, Funchal, Madeira, Portugal, March 22-23, 2018 (Cham: Springer), 180-195.

Simplican, S. C., Leader, G., Kosciulek, J., and Leahy, M. (2015). Defining Social Inclusion of People with Intellectual and Developmental Disabilities: An Ecological Model of Social Networks and Community Participation. Res. Develop. Disabilities 38, 18-29. doi:10.1016/j.ridd.2014.10.008

Story, M. F. (2011). “The Principles of Universal Design,” in Universal Design Handbook (McGraw-Hill Companies), Vol. 2, 58-67.

Uhlenberg, P. (Editor) (2009). International Handbook of Population Aging. Dordrecht: Springer. doi:10.1007/978-1-4020-8356-3

Wang, H., and Odoni, A. (2016). Approximating the Performance of a "Last Mile" Transportation System. Transportation Sci. 50 (2), 659-675. doi:10.1287/ trsc.2014.0553

Xie, Y., Danaf, M., Lima Azevedo, C., Akkinepally, A. P., Atasoy, B., Jeong, K., et al. (2019). Behavioral Modeling of On-Demand Mobility Services: General Framework and Application to Sustainable Travel Incentives. Transportation 46 (6), 2017-2039. doi:10.1007/s11116-019-10011-z

Conflict of Interest: The authors declare that the research was conducted in the absence of any commercial or financial relationships that could be construed as a potential conflict of interest.

Publisher's Note: All claims expressed in this article are solely those of the authors and do not necessarily represent those of their affiliated organizations, or those of the publisher, the editors and the reviewers. Any product that may be evaluated in this article, or claim that may be made by its manufacturer, is not guaranteed or endorsed by the publisher.

Copyright (c) 2022 Nanchen, Ramseyer, Grèzes, Wyer, Gervaix, Juon and Fragnière. This is an open-access article distributed under the terms of the Creative Commons Attribution License (CC BY). The use, distribution or reproduction in other forums is permitted, provided the original author(s) and the copyright owner(s) are credited and that the original publication in this journal is cited, in accordance with accepted academic practice. No use, distribution or reproduction is permitted which does not comply with these terms. 